\title{
Opioid prescribing patterns for non-malignant chronic pain for rural versus non-rural US adults: a population-based study using 2010 NAMCS data
}

Jacob P Prunuske ${ }^{1}$, Catherine A St. Hill ${ }^{2}$, Keri D Hager ${ }^{3}$, Andrine M Lemieux ${ }^{4}$, Michael T Swanoski $^{3}$, Grant W Anderson ${ }^{3}$ and M Nawal Lutfiyya ${ }^{3,5^{*}}$

\begin{abstract}
Background: Non-malignant chronic pain (NMCP) is one of the most common reasons for primary care visits. Pain management health care disparities have been documented in relation to patient gender, race, and socioeconomic status. Although not studied in relation to chronic pain management, studies have found that living in a rural community in the US is associated with health care disparities. Rurality as a social determinant of health may influence opioid prescribing. We examined rural and non-rural differences in opioid prescribing patterns for NMCP management, hypothesizing that distinct from education, income, racial or gender differences, rural residency is a significant and independent factor in opioid prescribing patterns.

Methods: 2010 National Ambulatory Medical Care Survey (NAMCS) data were examined using bivariate and multivariate techniques. NAMCS data were collected using a multi-stage sampling strategy. For the multivariate analysis performed the SPSS complex samples algorithm for logistic regression was used.

Results: In 2010 an estimated 9,325,603 US adults (weighted from a sample of 2745) seen in primary care clinics had a diagnosis of NMCP; $36.4 \%$ were prescribed an opioid. For US adults with a NMCP diagnosis bivariate analysis revealed rural residents had higher odds of having an opioid prescription than similar non-rural adults $(\mathrm{OR}=1.515,95 \% \mathrm{Cl} 1.513-1.518)$. Complex samples logistic regression analysis confirmed the importance of rurality and yielded that US adults with NMCP who were prescribed an opioid had higher odds of: being non-Caucasian ( $A O R=2.459,95 \% \mathrm{Cl} 1.194-5.066$ ), and living in a rural area (AOR $=2.935,95 \% \mathrm{Cl} 1.416-6.083$ ).

Conclusions: Our results clearly indicated that rurality is an important factor in opioid prescribing patterns that cannot be ignored and bears further investigation. Further research on the growing concern about the over-prescribing of opioids in the US should now include rurality as a variable in data generation and analysis. Future research should also attempt to document the ecological, sociological and political factors impacting opioid prescribing and care in rural communities. Prescribers and health care policy makers need to critically evaluate the implications of our findings and their relationship to patient needs, best practices in a rural setting, and the overall consequences of increased opioid prescribing on rural communities.
\end{abstract}

Keywords: NAMCS data, Rural health, Health care disparities, Opioids, Non-malignant chronic pain, NMCP

\footnotetext{
* Correspondence: nlutfiyy@umn.edu

${ }^{3}$ Department of Pharmacy Practice and Pharmaceutical Sciences, College of

Pharmacy, University of Minnesota, 1033 Kirby Drive, Duluth, MN, USA

${ }^{5}$ National Center for Interprofessional Education and Practice, University of

Minnesota, R685 Children's Rehab Center, 426 Church Street SE, Minneapolis,

MN 55455, USA

Full list of author information is available at the end of the article
}

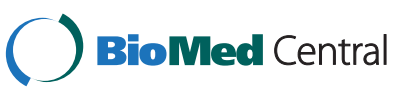

(c) 2014 Prunuske et al.; licensee BioMed Central Ltd. This is an Open Access article distributed under the terms of the Creative Commons Attribution License (http://creativecommons.org/licenses/by/2.0), which permits unrestricted use, distribution, and reproduction in any medium, provided the original work is properly credited. The Creative Commons Public Domain Dedication waiver (http://creativecommons.org/publicdomain/zero/1.0/) applies to the data made available in this article, unless otherwise stated. 


\section{Background}

Chronic pain, commonly defined as the experience of episodic or continuous debilitating pain over time (weeks to months or longer), is a significant problem in the United States [1-4]. It is a phenomenon with a complex etiology manifest with both physical and psychological components [4-6]. At present nearly 1 in 3 or 100 million adults in the US suffer from chronic pain [4,6]. Chronic pain in the US is estimated to cost approximately $\$ 560-\$ 635$ billion annually, an amount equal to about $\$ 2,000$ per capita [6]. This cost estimate includes both direct and indirect costs that are approximately equal to one another.

Chronic pain adversely impacts communities, families, and individuals by significantly contributing to poor mental and physical health resulting in lost work productivity and disability [4-7]. In the US, non-malignant chronic pain (NMCP) is one of the most common reasons for primary care visits $[1,3,8,9]$. At times when patients visit a healthcare professional for NMCP, inadequate training and resources may prevent proper assessment and management $[7,10,11]$. Pain management healthcare disparities have been documented in relation to patient gender [12,13], race $[3,11,14-16]$, and socioeconomic status $[12,17]$. Although not studied in relation to chronic pain management, studies have found that living in a rural community in the US is associated with healthcare disparities [18].

Opioids are commonly used in chronic pain management. Opioids are being overprescribed with possible negative consequences for individuals, families and communities. These consequences include: unintended death [7], overdose [7], diversion [7], and crime [7]. There is an upward trend for overprescribing opioids. Rurality as a social determinant of health may influence opioid prescribing [18]. Some research has been conducted on different types of chronic pain and opioid prescribing patterns including a geographic variable in the analysis. However, none of these studies undertook the task of answering a question about opioid prescribing and NMCP in rural versus non-rural adults using patient level health records [19-22]. This has created an epidemiological gap in our knowledge regarding opioid prescribing patterns for rural adults with NMCP.

Rasu, et al. [4] studied chronic pain management (medication and non-medication) in US ambulatory care settings. While they described the characteristics of their patient population, they did not examine the associations between patient characteristics and variations in prescribing patterns. They concluded that additional research should investigate patterns of NMCP management in various populations. Others $[23,24]$ have done this, but with older data. One study included geographic location of physician practice site in their analyses using rural locale as the reference category in multivariate analyses and found no significant relationship to opioid prescribing [25]. In this paper we hypothesize that distinct from patient race, education, income or gender, rural residency is a significant and an independent risk factor for the greater probability of receiving an opioid prescription for NMCP.

\section{Methods}

To answer the research question, 2010 National Ambulatory Medical Care Survey (NAMCS) data were examined using bivariate and multivariate techniques. NAMCS is designed to collect data on the utilization and provision of ambulatory care services nationwide. Data are collected from a national sample of ambulatory care visits. The survey employs a complex four-stage probability sampling design. A description of the sampling strategy is discussed elsewhere [25]. The 2010 NAMCS data were used for this study because they were the most recently available data. These data are weighted to be nationally representative of patient health records.

All analyses were performed on weighted data as is recommended by the Center for Disease Control and Prevention's (CDC) National Center for Health Statistics (NCHS). The weighting, as calculated, uses the most recently available census data to provide a stratified representation of the nation's patient population. Results report weighted data.

The survey uses a Patient Record Form as the survey instrument. The NAMCS patient record form is completed by ambulatory care staff for a systematic random sample of patient visits during a randomly assigned 1-week reporting period. Data are obtained on demographic characteristics of patients, expected source(s) of payment, patients' complaints, diagnoses, diagnostic/screening services, procedures, medication therapy, disposition, types of providers seen, causes of injury, and certain characteristics of the facility, such as geographic region and metropolitan status.

Rurality, one of the key independent variables in this analysis, was derived using Metropolitan and Micropoli$\tan$ Statistical Area (MSA) methodology. This is a definition used by federal level agencies for research purposes. MSA was recoded into the dichotomous categories of rural or non-rural. Rural residents were defined as people living either within an MSA that had no center city or outside an MSA. Non-rural residents included all respondents living in a center city of an MSA, outside the center city of an MSA but inside the county containing the center city, or inside a suburban county of an MSA.

The study population for this research was US adults with NMCP. NMCP is defined as pain lasting 3 months or more or as pain persisting beyond the time of expected healing. The three-digit ICD-9 code for NMCP is 338.2. The covariates or independent variables for this research were: geographic locale (rural/non-rural), 
patient sex (male/female), race/ethnicity (Caucasian/ Non-Caucasian), age ranges (18-39/40-64/65 years and older), education attainment in a patient's zip code $(\leq 20 \%$ of adults with a university degree/> $20 \%$ of adults with a university degree), poverty level in patient's zip code $(<10 \% / \geq 10 \%)$ health insurance status (insured/noninsured), primary health care provider (HCP) seen (yes/no), depression diagnosis (yes/no), arthritis diagnosis (yes/no). Depression and arthritis diagnoses were included as variables because these may influence opioid prescribing [26,27]. All of the study covariates were recoded from their original configuration for analyses. Re-coding entailed either collapsing categories and/or removing unknown responses. Opioid prescription was the dependent variable for this study.

The study variable that entailed complicated re-coding was the dependent variable-opioid prescription. Using the CDC's New Ambulatory Care Drug Database System for NAMCS Data, prescribed drugs were classified as opioid or other. Table 1 displays the opioid drug codes by generic drug name.

Statistical Package for Social Scientists (SPSS, IBM, Chicago, IL, version 21.0) was used to complete all statistical analyses and alpha was set at $\mathrm{p}<0.05$. Bivariate contingency table analysis was conducted to establish the relationships between each of the covariates and the dependent variable. Bivariate analysis tests for a statistically significant relationship between an outcome or dependent variable and a predictor or independent variable. Bivariate analysis is not a stratified analysis. SPSS allows an unadjusted odds ratio to be computed from the contingency table analysis as long as the contingency table is a $2 \times 2$ table. If not, then a chi square may be computed as the test statistic for differences between percentages (e.g., 3-group age ranges and opioid prescription). Logistic regression analysis, to produce adjusted measures, was performed using SPSS (version 21.0) complex samples. The complex samples algorithm was used to account for the stratified, clustered, and weighted variables in the 2010 NAMCS survey data. This was essential since NAMCS data are collected using a survey design where a nationally representative sample of physicians and practice sites are examined and sample weights applied to obtain national populationbased statistics. Detailed documentation of the NAMCS instrument, methodology, and data files that served as the basis for this study is available elsewhere [25]. The multivariate logistic regression model was performed using opioid prescription as the dependent variable, and adjusted odds ratios were produced to test significance and establish effects sizes. US adults with a diagnosis of NMCP was the population examined. For analysis the sample of 2,745 was weighted to represent 9,325,603 US adults with a diagnosis of NMCP.
The Institutional Review Boards (IRBs) at all of the researchers' institutions recognize that the analysis of deidentified, publicly available data does not constitute human subjects research as defined in federal regulations and as such does not require IRB review. Hence, human subjects' approval was not necessary since this was a deidentified data only study.

\section{Results}

An estimated 9,325,603 US adults with a diagnosis of NMCP were seen in primary care clinics in 2010 in the US. Table 2 displays data describing the study population -- US adults with NMCP. The data are displayed by the independent covariates and the dependent variable (opioid prescription) and are those used to perform the complex samples logistic regression analysis. Missing data were removed from the analysis as displayed in Table 2.

The majority of the population $94.4 \%$ had health insurance and $66.4 \%$ were reported as having seen their primary HCP. Over seventy percent $(73.7 \%)$ of the study population were women and $79.4 \%$ were Caucasian. In terms of the dependent variable $36.4 \%$ of the adult population with NMCP had an opioid prescription.

Bivariate analysis performed indicated that all of the study's independent variables or covariates were significantly associated with the dependent variable (Table 3). Most importantly this bivariate analysis revealed that rural adults with NMCP had higher odds $(\mathrm{OR}=1.515$, $95 \% \mathrm{CI}=1.513-1.518$ ) than similar non-rural adults of having a prescription for opioids.

Complex samples logistic regression was performed and the results are displayed in Table 4. Based on the bivariate analysis all of the study covariates were entered into the complex samples logistic regression model. Analysis yielded that two covariates were significantly associated with the dependent variable--rural residency (AOR $=2.935,95 \%$ CI 1.416-6.083) and non-Caucasian race/ethnicity $(\mathrm{AOR}=2.459,95 \% \mathrm{CI} 1.194-5.066)$.

\section{Discussion}

Recently there has been much concern expressed about the over-prescribing of opioids [7,28-30]. This concern arises from the fact that opioids are potentially addictive which can lead to misuse. Opioids have been cited as contributing to unnecessary morbidity and mortality, and in the long-run contribute to potentially unnecessary medical costs $[4,28]$. We were interested in examining differences in rural and non-rural opioid prescribing patterns for NMCP management, hypothesizing that disparities exist in opioid prescribing patterns for rural populations in the US. Our analyses supported our hypothesis that rural residency is an independent risk factor for a greater probability of patients with NMCP being prescribed an opioid. 
Table 1 Opioid drug codes by generic drug name

\section{Opioid drug codes from NAMCS drug database}

25510, 5660, 8335

2387,97062

1187,50040

9286

2333, 5081, 5091, 8246, 9582, 22303, 91047, 96109, 97181

$7117,7223,21575$

$23285,30535,30540$

8338

7420, 8475, 8490, 10115

91046, 92044, 92070, 98144, 99123

21550,60990

8606,98067

3064, 9969, 21860, 21870, 21875, 21880, 22720, 22845

22850

1288,1314

95085

17340, 17362

$200,8785,18760,96045$

10130, 18985

85, 2852, 3228, 8079, 10743, 19650, 19699, 26763, 41420, 60940, 70214

91071

9574

2067, 3307, 7197, 9508, 29645, 60565, 92024, 94188

14770, 92041, 92042

$7582,9435,14955,94184$

9600, 9641, 15005

$11225,22415,27315$

11090, 18425, 24770, 25525

8910

5054, 60265, 95036

5103

1021, 29285

1028, 7180, 71857190

25690

91012

10715

42245

40765

13152, 24143

866,96145

21095

2730,2735

\section{Generic drug name}

Propoxyphene

Remifentanil

Sufentanil

Tapentadol

Oxycodone

Oxymorphone

Pentazocine

Phenerol

Propoxyphene

Morphine

Nalbuphine

Narcotic Analgesics

Opium

Opium-Sodium Bicarbonate

Oxycodone

Hydroxyzine-Meperidine

Levorphanol

Meperidine

Methadone

Morphine

Dezocine

Dihydrocodeine

Fentanyl

Homatropine Methyl Bromide-Hydrocodone

Hydrocodone

Hydromorphone

Aspirin; Caffeine; Codeine; Phenacetin

Aspirin; Caffeine; Phenacetin; Propoxyphene

Atropine; Opium; Phenacetin; Salicylamide

Buprenorphine

Butalbital-Codeine

Butorphanol

Codeine

Codeine; Sanguinaria; Terpin Hydrate; White Pine Syrup; Wild Cherry Syrup

Dezocine

Acetaminophen; Aspirin; Caffeine;

Dihydrocodeine

Acetaminophen; Aspirin; Caffeine; Hydrocodone

Acetaminophen; Butabarbital; Codeine

Acetaminophen; Butalbital; Codeine

Alfentanil

Alphaprodine

Aluminum Hydroxide; Aspirin; Codeine; Magnesium Antacids 
Table 1 Opioid drug codes by generic drug name (Continued)

\begin{tabular}{|c|c|}
\hline 2740 & $\begin{array}{l}\text { Aluminum Hydroxide; Aspirin; Codeine; } \\
\text { Magnesium Hydroxide }\end{array}$ \\
\hline 12560 & Aspirin; Butalbital; Caffeine; Codeine; Phenacetin \\
\hline $45,50,55,65,1990,2815,2825,11220$ & Aspirin; Caffeine; Codeine; Phenacetin \\
\hline 3520 & Acetaminophen; Codeine; Salicylamide \\
\hline 6284 & $\begin{array}{l}\text { Acetaminophen; Ethanol; Glycerin; Hydrocodone; } \\
\text { Parabens }\end{array}$ \\
\hline $\begin{array}{l}250,265,270,275,280,1758,2340,2345,5151,5640,7080,7165,7618,9538,11265,11268,23665, \\
23670,23675,23680,25635,28215,32910,32915,32920,32925,32930,32935,41245,91010\end{array}$ & Acetaminophen-Codeine \\
\hline 197 & Acetaminophen-Dextropropoxyphene \\
\hline 10128,40415 & Acetaminophen-Dihydrocodeine \\
\hline $\begin{array}{l}251,1268,1995,2045,2082,2132,2314,3518,6059,7064,8354,10105,14917,34110,40860,60340, \\
61610,89038,89039,92180,93077,93089,96028,96047,98036,98168\end{array}$ & Acetaminophen-Hydrocodone \\
\hline 8790 & Acetaminophen-Meperidine \\
\hline $283,2348,3394,7251,7252,7632,8248,22305,22306,23385,26958,28272,32945,91048,99114$ & Acetaminophen-Oxycodone \\
\hline 7701,30513 & Acetaminophen-Pentazocine \\
\hline $156,6232,8470,25530,25545,28340,34985,61240,89071,89072,93053,93411$ & Acetaminophen-Propoxyphene \\
\hline 11689,95178 & Apap; Butalbital; Caffeine; Codeine \\
\hline $44,3078,7467,93351$ & Apap; Caffeine; Dihydrocodeine \\
\hline $12555,12565,12570,15983,40020$ & Asa; Butalbital; Caffeine; Codeine \\
\hline 30340 & Asa; Caffeine; Dihydrocodeine \\
\hline $4215,8480,10120,25505,25515,25520,28345,41375$ & Asa; Caffeine; Propoxyphene \\
\hline 5018 & Aspirin; Buffers; Codeine \\
\hline 10285 & Aspirin; Caffeine; Dover's Powder \\
\hline $105,2803,2820,11230,11235,11240,11245,11250,11255,11260$ & Aspirin-Codeine \\
\hline $8397,92181,93027$ & Aspirin-Hydrocodone \\
\hline $1099,2828,22307,22308,23390,23395,58273,93250$ & Aspirin-Oxycodone \\
\hline 30530 & Aspirin-Pentazocine \\
\hline 8485,8495 & Aspirin-Propoxyphene \\
\hline 2943,2955 & Atropine-Meperidine \\
\hline 19655 & Atropine-Morphine \\
\hline 3245,21865 & Belladonna-Opium \\
\hline 9516 & Bupivacaine-Hydromorphone \\
\hline 3276 & Buprenorphine-Naloxone \\
\hline 15650,89034 & Droperidol-Fentanyl \\
\hline $9737,9751,98043$ & Hydrocodone-lbuprofen \\
\hline 5040 & Ibuprofen-Oxycodone \\
\hline 1098, 4534, 8093, 18755, 96012 & Meperidine-Promethazine \\
\hline 4538 & Naloxone-Pentazocine \\
\hline
\end{tabular}

This research yielded important findings. First, rural residents had higher odds of having an opioid prescription than similar non-rural adults. Rural residency was the strongest predictor for having an opioid prescription and a diagnosis for NMCP. Second, being non-Caucasian was a strong predictor of having an opioid prescription and a diagnosis for NMCP.
Our results clearly indicate that rurality is an important factor in opioid prescribing patterns that cannot be ignored and bears further investigation. This is in stark difference to the finding of an earlier paper [24] that found no relationship between opioid prescription and geographic locale. At first glance one might conclude that this finding indicates an opioid prescribing disparity, 
Table 2 Description of the study population (adults with NMCP) for SPSS complex samples logistic regression analysis

\begin{tabular}{|c|c|c|c|}
\hline \multicolumn{2}{|l|}{ Variables and Factors } & \multirow{2}{*}{$\begin{array}{l}\text { Weighted N* } \\
6868340\end{array}$} & \multirow{2}{*}{$\frac{\text { Weighted \% }}{73.7}$} \\
\hline Patient sex & Female & & \\
\hline & Male & 2457263 & 26.3 \\
\hline \multirow[t]{3}{*}{ Patient age } & $18-39$ & 565172 & 6.1 \\
\hline & $40-64$ & 4070522 & 43.6 \\
\hline & $>=65$ & 4689909 & 50.3 \\
\hline \multirow[t]{2}{*}{ Race/Ethnicity } & Caucasian & 7406401 & 79.4 \\
\hline & Non-Caucasian & 1919202 & 20.6 \\
\hline \multirow{2}{*}{$\begin{array}{l}\text { Education percent of } \\
\text { university graduates } \\
\text { in patient zip code }\end{array}$} & $<20 \%$ & 5001646 & 53.6 \\
\hline & $>=20 \%$ & 4323957 & 46.4 \\
\hline \multirow{2}{*}{$\begin{array}{l}\text { Poverty percent in } \\
\text { patient zip code }\end{array}$} & $<10 \%$ & 4988235 & 53.5 \\
\hline & $>=10 \%$ & 4337368 & 46.5 \\
\hline \multirow{2}{*}{$\begin{array}{l}\text { Health Insurance } \\
\text { status }\end{array}$} & Have Health Insurance & 8805283 & 94.4 \\
\hline & $\begin{array}{l}\text { Do Not Have } \\
\text { Health Insurance }\end{array}$ & 520320 & 5.6 \\
\hline \multirow[t]{2}{*}{ Primary HCP visit } & Yes & 6195674 & 66.4 \\
\hline & No & 3129929 & 33.6 \\
\hline \multirow{2}{*}{$\begin{array}{l}\text { Patient now has } \\
\text { arthritis }\end{array}$} & No & 5087784 & 54.6 \\
\hline & Yes & 4237819 & 45.4 \\
\hline \multirow{2}{*}{$\begin{array}{l}\text { Patient now has } \\
\text { depression }\end{array}$} & No & 7726881 & 82.9 \\
\hline & Yes & 1598722 & 17.1 \\
\hline \multirow{2}{*}{$\begin{array}{l}\text { Geographic locale } \\
\text { of patient }\end{array}$} & Rural & 1966383 & 21.1 \\
\hline & Non-Rural & 7359220 & 78.9 \\
\hline \multirow[t]{2}{*}{ Opioid prescription** } & Other Medications & 5928705 & 63.6 \\
\hline & Opioids & 3396898 & 36.4 \\
\hline
\end{tabular}

*This weighted $\mathrm{n}$ is derived from a sample size of 2745 , of which $2272(82.8 \%)$ were non-rural residents and $473(17.2 \%)$ rural residents.

**Study Dependent Variable.

NAMCS 2010 Data (weighted $n=9,325,603$ ).

but that may be too simple an explanation. All differences are not disparities. Disparities arise when the differences are avoidable as well as unjust $[3,18]$. We cannot say with any certainty that these are the characteristics of the differences revealed in prescribing patterns from our analyses. It may be that there are treatment option limitations in rural areas of the US [31]. Ultimately, NMCP is complex and often requires a multifactorial approach for optimal management [32]. For instance, physical therapy, occupational therapy, massage therapy, acupuncture, integrated specialty pain management services, or behavioral modification may be useful approaches for the management of patients with NMCP [33]. These modalities as treatment options may be less available to patients in the rural US [31].

Our findings also identified that non-Caucasian race/ ethnicity (African American, Hispanic, Asian, Native American, and multiracial) was an independent risk factor for having NMCP and being prescribed an opioid. Opioid prescribing patterns for non-Caucasian adults is complicated and the differences between our findings and those from a number of other studies are hard to reconcile or explain. Findings from multiple studies have yielded that African American or Black patients were less likely than Caucasian ones to be prescribed opioids for pain [12,15,16,19,34-37]. Other research has revealed that in the US there is little difference in the estimated prevalence of pain across population groups [38]. However, racial/ethnic minorities have often had inadequate pain management despite being more likely to report experiencing severe pain and/or pain that interfered with daily activities $[3,38]$. One explanation for the variance of our findings from other studies might be the examination of data from a different source. The NAMCS data analyzed in this study is derived from patient health records rather than patient self-report surveys. Patient health record data are based on documented visits to health care providers, while patient self-report data are not. We do not want to make a claim of the veracity of one source of data over the other, only that the analysis of each may yield different findings.

\section{Study limitations and strengths}

This study does have some limitations, most of which are attributable to how the survey data were collected. First, ICD-9 codes were used to identify patients with NMCP and to limit the population included in the study. Second, opioid prescriptions were then assumed to be linked to the NMCP patient population. Since there is no link in the questionnaire form between prescribed medications (in our case opioids) and diagnosis (ICD-9 codes), we were unable to determine with surety for what diagnosis opioids were being prescribed for. However, this limitation is also present in a previously published study [4], setting precedence for using this methodology. Studies that can determine causality amongst these variables are warranted. Third, the variables of race/ethnicity, education, and household income were derived variables.

Nevertheless, this study has a number of strengths. Since we used national patient record population-level survey data, we had a large data set that was weighted to ensure that our findings could be more easily and accurately generalized to the US population. Another strength is the magnitude of the effect sizes for rural and nonrural opioid prescribing patterns as well as those detected for race/ethnicity. The effect sizes, derived from the logistic regression odds ratios, ranged from nearly two to three times greater than the reference categories. Much has been studied in reference to age and race/ethnicity, but these findings lend vigorous support to the conceptualization of rurality as a social determinant of health. 
Table 3 Bivariate analysis of US adults with a diagnosis of chronic pain and an opioid prescription as dependent variable by covariates

\begin{tabular}{lll}
\hline Variable & Factor & Unadjusted odds ratio $(\mathbf{9 5} \% \mathbf{C l})$ \\
\hline Patient sex (vs. Male) & Female & $1.107(1.104,1.109)$ \\
Patient Race/Ethnicity (vs. Non-Caucasian) & Caucasian & $.643(.642, .644)$ \\
Education percent university graduate in patient zip code (vs. > =20\%) & $<20 \%$ & $1.010(1.008,1.012)$ \\
Poverty percent in patient zip code (vs. > = 10\%) & $<10 \%$ & $1.036(1.034,1.037)$ \\
Health Insurance status (vs. Do Not Have Health Insurance) & Have Health Insurance & $1.010(1.006,1.014)$ \\
Primary HCP visit (vs. No) & Yes & $1.192(1.190,1.194)$ \\
Patient now has arthritis (vs. Yes) & No & $.885(.883, .886)$ \\
Patient now has depression (vs. Yes) & No & $1.299(1.295,1.302)$ \\
Geographic local (vs. Non-Rural) & Rural & $1.515(1.513,1.518)$ \\
Variable & Factors & $\%$ \\
Patient age range & $18-39$ & 6.1 \\
& $40-64$ & 43.6 \\
\hline
\end{tabular}

2010 NAMCS (weighted $\mathrm{n}=9,325,603$ ).

Table 4 SPSS complex samples logistic regression analysis of US adults with NMCP (study dependent variable $=$ opioid prescription)

\begin{tabular}{|c|c|c|}
\hline Variables & Factors & $\begin{array}{l}\text { Adjusted odds } \\
\text { ratio }(95 \% \mathrm{Cl})\end{array}$ \\
\hline \multirow[t]{2}{*}{ Patient sex } & Female & $1.310(.631,2.720)$ \\
\hline & Male & $--^{*}$ \\
\hline \multirow[t]{3}{*}{ Patient age } & $18-39$ & $1.094(.297,4.027)$ \\
\hline & $40-64$ & $1.949(.977,3.887)$ \\
\hline & $>=65$ & $--^{*}$ \\
\hline \multirow[t]{2}{*}{ Race/Ethnicity } & Caucasian & $--^{*}$ \\
\hline & Non-Caucasian & $2.459(1.194,5.066)$ \\
\hline \multirow{2}{*}{$\begin{array}{l}\text { Education percent of } \\
\text { university graduates } \\
\text { in patient zip code }\end{array}$} & $<20 \%$ & $--^{*}$ \\
\hline & $>=20 \%$ & $1.031(.489,2.175)$ \\
\hline \multirow{2}{*}{$\begin{array}{l}\text { Poverty percent in } \\
\text { patient zip code }\end{array}$} & $<10 \%$ & $1.713(.876,3.351)$ \\
\hline & $>=10 \%$ & $--^{*}$ \\
\hline \multirow[t]{2}{*}{ Primary HCP visit } & Yes & $1.162(.515,2.621)$ \\
\hline & No & $--^{*}$ \\
\hline \multirow[t]{2}{*}{ Health Insurance status } & $\begin{array}{l}\text { Have Health } \\
\text { Insurance }\end{array}$ & $1.371(.584,3.221)$ \\
\hline & $\begin{array}{l}\text { Do Not Have } \\
\text { Health Insurance }\end{array}$ & $--^{*}$ \\
\hline \multirow[t]{2}{*}{ Patient now has arthritis } & Yes & $1.309(.514,3.333)$ \\
\hline & No & $--^{*}$ \\
\hline \multirow{2}{*}{$\begin{array}{l}\text { Patient now has } \\
\text { depression }\end{array}$} & Yes & $.518(.246,1.089)$ \\
\hline & No & $--^{*}$ \\
\hline \multirow[t]{2}{*}{ Geographic locale } & Rural & $2.935(1.416,6.083)$ \\
\hline & Non-Rural & $--^{*}$ \\
\hline
\end{tabular}

*Reference category.

NAMCS 2010 data (weighted $n=9,325,603$ ).

\section{Conclusions}

This study fills an important epidemiological knowledge gap regarding opioid prescribing patterns for rural adults with NMCP. Further research on the growing concern about the over-prescribing of opioids in the US should now include rurality as a variable in data generation and analysis in addition to the variable of race/ethnicity that are commonly included. In order to provide the best level of care to all patients regardless of geographic location or race/ethnicity, another level of analysis should capture data on opioid dosing and health care provider perceptions of patients. Future research should also attempt to document the ecological, sociological and political factors impacting opioid prescribing and care in rural communities. Prescribers and health care policy makers need to critically evaluate the implications of our findings and their relationship to patient needs, best practices in a rural setting, and the overall consequences of increased opioid prescribing on rural communities.

\section{Abbreviations}

AOR: Adjusted odds ratios; CDC: Centers for disease control and prevention; HCP: Health care provider; IRB: Institutional Review Board; MSA: Metropolitan Statistical Area; NAMCS: National Ambulatory Medical Care Survey; NCHS: National Center for Health Statistics; NMCP: Non-Malignant Chronic Pain; OR: Odds ratios; SPSS: Statistical Package for Social Scientists.

\section{Competing interests}

The authors' declare that they have no competing interests.

\section{Authors' contributions}

JPP, KDH, AML, MTS, CAStH, GWA and MNL all made substantial

contributions to the conception and design of the manuscript, contributed to the interpretation of the data, were involved in revising the manuscript critically for important intellectual content, and have given final approval of this version of the manuscript to be published. Additionally, MNL oversaw the statistical analyses and the acquisition of the data. 


\section{Authors' information}

Jacob P Prunuske, Catherine A St. Hill, Keri D Hager, Andrine M Lemieux, Michael T. Swanoski, Grant W Anderson and May N Lutfiyya as members of the Interprofessional Faculty Research Fellowship Program in the College of the Pharmacy at the University of Minnesota contributed equally to this project.

\section{Disclosure}

This research was supported by the College of Pharmacy at the University of Minnesota and the National Center for Interprofessional Education and Practice at the University of Minnesota.

\section{Author details}

${ }^{1}$ Department of Family Medicine and Community Health, School of Medicine, University of Minnesota, Duluth, MN, USA. ${ }^{2}$ Department of Experimental and Clinical Pharmacology, College of Pharmacy, University of Minnesota, 308 Harvard St. SE, Minneapolis, MN, USA. ${ }^{3}$ Department of Pharmacy Practice and Pharmaceutical Sciences, College of Pharmacy, University of Minnesota, 1033 Kirby Drive, Duluth, MN, USA. ${ }^{4}$ Behaviora Medicine Laboratory, School of Medicine, University of Minnesota, 1033 Kirby Drive, Duluth, MN, USA. ${ }^{5}$ National Center for Interprofessional Education and Practice, University of Minnesota, R685 Children's Rehab Center, 426 Church Street SE, Minneapolis, MN 55455, USA

Received: 31 January 2014 Accepted: 24 October 2014

Published online: 19 November 2014

\section{References}

1. Dubois MY, Gallagher RM, Lippe PM: Pain medicine position paper. Pain Med 2009, 10:972-1000.

2. International Association for the Study of Pain (IASP). Pain 1979, 6:250

3. Mossey JM: Defining racial and ethnic disparities in pain management. Clin Orthop Relat Res 2011, 469:1859-1870.

4. Rasu RS, Sohraby R, Cunningham L, Knell ME: Assessing chronic pain treatment practices and evaluating adherence to chronic pain clinical guidelines in outpatient practices in the United States. J Pain 2013, 6:568-578.

5. American Academy of Pain Medicine: AAPM Facts and Figures on Pain Available at: http://www.painmed.org/patient/facts.html. Accessed 13 November 2013

6. Committee on Advancing Pain Research, Care, and Education; Institute of Medicine: Relieving Pain in America: A Blueprint for Transforming Prevention, Care, Education and Research. Available at: http://www.nap. edu/catalog.php?record id=131722. Accessed 13 November 2013

7. Okie S: A flood of opioids, a rising tide of deaths. N Engl J Med 2010 363:1981-1984.

8. Hardt J, Jacobsen C, Goldberg J, Nickel R, Buchwald D: Prevalence of chronic pain in a representative sample in the United States. Pain Med 2008, 9:803-812.

9. Stewart WF, Ricci JA, Chee E, Morganstein D, Lipton R: Lost productive time and cost due to common pain conditions in the US workforce. JAMA 2003, 290:2443-2454

10. Califano JA: Under the counter: The diversion and abuse of controlled prescription drugs in the US. The National Center on Addiction and Substance Abuse: Columbia University: 2005

11. Meltzer EC, Rybin D, Saitz R, Samet JH, Schwartz SL, Butler SF, Liebschutz JM: Identifying prescription opioid use disorder in primary care: Diagnostic characteristics of the Current Opioid Misuse Measure (COMM). Pain 2011, 152:397-402.

12. Heins JK, Heins A, Grammas M, Costello M, Huang K, Mishra S: Disparities in analgesia and opioid prescribing practices for patients with musculoskeletal pain in the emergency department. J Emerg Nurs 2006, 32:219-224.

13. Marcus D: Gender and ethnic differences in pain. Experience Chronic Pain: A Primary Care Guide to Practical Management. Humana Press (a part of Springer Science + Business Media, LLC). 2009

14. Crowley-Matoka M: How to parse the protective, the punitive and the prejudicial in chronic opioid therapy. Pain 2013, 154:5-6.

15. Hausmann LRM, Gao S, Lee ES, Kwoh CK: Racial disparities in the monitoring of patients on chronic opioid therapy. Pain 2013, 154:46-52.

16. Shavers VL, Bakos A, Sheppard VB: Race, ethnicity and pain among the U. S. adult population. J Health Care Poor Underserved 2010, 21:177-220.

17. Coffey RM, Andrews RM, Moy E: Racial, ethnic, and socioeconomic disparities in estimates of AHRQ patient safety indicators. Med Care 2005, 43:S148-s157.
18. Lutfiyya MN, McCullough JE, Haller IV, Waring SC, Bianco JA, Lipsky MS: Rurality as a root or fundamental social determinant of health. Disease a Month 2012, 58:620-628.

19. Pletcher MJ, Kertesz SG, Kohn MA, Gonzales R: Trends in opioid prescribing by race/ethnicity for patients seeking care in US emergency departments. JAMA 2008, 299:70-78.

20. Curtis LH, Stoddard J, Radeva Jl, Hutchison S, Dans PE, Wright A, Woosley RL, Schulman KA: Geographic variation in the prescription of schedule II opioid analgesics among outpatients in the United States. Health Serv Res 2006, 41:856-858.

21. McDonald DC, Carlson K, Izrael D: Geographic variation in opioid prescribing in the U.S. J Pain 2012, 13:988-996.

22. Zerzan JT, Morden NE, Soumerai S, Ross-Degnan D, Roughead E, Zhang F, Simoni-Wastila L, Sullivan SD: Trends and geographic variation of opiate medication use in state Medicaid fee-for-service programs, 1996 to 2002. Med Care 2006, 44:1005-1010.

23. Kelly JP, Cook SF, Kaufman DW, Anderson T, Rosenberg L, Mitchell AA: Prevalence and characteristics of opioid use in the US adult population. Pain 2008, 138:507-513.

24. Olsen Y, Daumit GL, Ford DE: Opioid prescriptions by U.S. primary care physicians from 1992 to 2001. J Pain 2006, 7:225-235

25. National Ambulatory Medical Care Survey: National Ambulatory Medical Care Survey. ; 2013. Available at: http://www.cdc.gov/nchs/about/major/ahcd/ ahcd1.htm. Accessed 13 November 2013.

26. Grattan A, Sullivan MD, Saunders KW, Campbell Cl, Von Korf MR: Depression and prescription opioid misuse among chronic opioid therapy recipients with no history of substance abuse. Ann Fam Med 2012, 10:304-311.

27. Stein C, Baerwald C: Opioids for the treatment of arthritis pain. Expert Opin Pharmacother 2014, 15:193-202.

28. Chou R, Ballantyne JC, Fanciullo GJ, Fine PG, Miaskowski C: Research gaps on use of opioids for chronic non cancer pain: findings from a review of the evidence for an American pain society and American academy of pain medicine clinical practice guideline. J Pain 2009, 10:147-159.

29. Pizzo PA, Clark NM: Alleviating suffering 101 — pain relief in the United States. N Engl J Med 2012, 366:197-199.

30. Sehgal N, Manchikanti L, Smith HS: Prescription Opioid Abuse in Chronic Pain: A Review of Opioid Abuse Predictors and Strategies to Curb Opioid Abuse. Pain Physician 2012, 15:ES67-ES92.

31. Hoffman PK BS, Meier BP MS, Council JR: A comparison of chronic pain between an urban and rural population. J Community Health Nurs 2002, 19:213-224

32. Reid MC, Engles-Horton LL, Weber MB, Kerns RD, Rogers EL, O'Connor PG: Use of opioid medications for chronic non cancer pain syndromes in primary care. J Gen Intern Med 2002, 17:173-179.

33. Breivik H: Opioids in chronic non-cancer pain, indications and controversies. Eur J Pain 2000, 9:127-130

34. Chen I, Kurz J, Pasanen M, Faselis C, Panda M, Staton L, O'Rorke J, Menon M, Genao I, Wood J, Mechaber AJ, Rosenberg E, Carey T, Calleson D, Cykert S: Racial differences in opioid use for chronic nonmalignant pain. $J$ Gen Intern Med 2005, 20:593-598.

35. Tamayo-Sarver JH, Dawson NV, Hinze SW, Cydulka RK, Wigton RS, Albert JM, Ibrahim SA, Baker DW: The effect of race/ethnicity and desirable social characteristics on physicians' decisions to prescribe opioid analgesics. Acad Emerg Med 2003, 10:1239-1248.

36. Tamayo-Sarver JH, Hinze SW, Cydulka RK, Baker DW: Racial and ethnic disparities in emergency department analgesic prescription. Am J Public Health 2003, 93:2067-73

37. Terrell KM, Hui SL, Castelluccio P, Kroenke K, McGrath RB, Miller DK Analgesic prescribing for patients who are discharged from an emergency department. Pain Med 2010, 11:1072-7.

38. Stinson FS, Grant BF, Dawson DA, Ruan WJ, Huang B, Saha T: Comorbidity between DSM-IV alcohol and specific drug use disorders in the United States: results from the National Epidemiologic Survey of Alcohol and Related Conditions. Drug Alcohol Depend 2005, 80:105-116.

doi:10.1186/s12913-014-0563-8

Cite this article as: Prunuske et al:: Opioid prescribing patterns for non-malignant chronic pain for rural versus non-rural US adults: a population-based study using 2010 NAMCS data. BMC Health Services Research 2014 14:563. 